\title{
A Rare Case of Arytenoid Cyst presenting as Dysphagia
}

\author{
${ }^{1} S$ Gnanatilakan, ${ }^{2}$ Vishal Prasad, ${ }^{3} \mathrm{R}$ Jeyalakshmi
}

\section{ABSTRACT}

Objective: To report a rare benign condition of larynx in a very rare subsite. To emphasize on the role of coblator in the treatment of laryngeal cysts and to highlight the fact that arytenoid cyst should be considered in the differential diagnosis of dysphagia and hoarseness.

Case report: A 76-year-old adult male, Resident of Trichy, Tamil Nadu, Presented with Discomfort in throat-2 years, Change of voice-2 months and Dysphagia-2 months. Indirect Laryngoscopy and Flexible Laryngoscopy revealed a mass in the right arytenoid which was pedunculated and filling the supraglottis. The airway was however adequate. Contrast Enhanced CT scan of the neck revealed a cystic soft tissue mass arising from Right arytenoids extending into supraglottis. A provisional diagnosis of Arytenoid cyst was made. The patient underwent Direct Laryngoscopy and coblator assisted excision of the cyst under General Anesthesia.

Conclusion: This case report highlights the fact that an arytenoid cyst, although rare, must be considered in the differential diagnosis of any case presenting with dysphagia and/or hoarseness.

It also explains the role of coblation in the management of such lesions.

Keywords: Arytenoid cyst, Laryngeal cyst, Coblation, Dysphagia.

How to cite this article: Gnanatilakan S, Prasad V, Jeyalakshmi R. A Rare Case of Arytenoid Cyst presenting as Dysphagia. Int J Phonosurg Laryngol 2014;4(2):80-82.

\section{Source of support: Nil}

Conflict of interest: None

\section{INTRODUCTION}

Arytenoid cyst is a very rare entity. This may be asymptomatic many a times. In symptomatic individuals, they may present with dysphagia, hoarseness or even stridor. Here we present an interesting case of epidermoid cyst of the right arytenoid which was successfully treated by coblation.

\footnotetext{
${ }^{1}$ Professor, ${ }^{2}$ Assistant Professor, ${ }^{3}$ Consultant

${ }^{1}$ Department of ENT, Tilak Hospital, Tiruchirappalli, Tamil Nadu, India ${ }^{2}$ Department of ENT, Sri Devaraj Urs Medical College, Kolar Karnataka, India

${ }^{3}$ Department of ENT, Bharat Heavy Electricals Limited, Ranipet Tamil Nadu, India

Corresponding Author: Vishal Prasad, Assistant Professor Department of ENT, Sri Devaraj Urs Medical College, Kolar Karnataka, India, Phone: 8105185861, e-mail: drvishal_prasad@ yahoo.co.in
}

\section{CASE REPORT}

A 76-year-old adult male, resident of Trichy, Tamil Nadu presented to Main Hospital, BHEL, Trichy with discomfort in throat of 2 years, change of voice and dysphagia of 2 months duration. There was no history of dyspnea, otalgia, neck swelling or addictions. Patient was diagnosed as having arytenoid cyst 2 years ago in our hospital but had refused further treatment as he was asymptomatic. On evaluation with indirect laryngoscopy and flexible laryngoscopy, a cystic, pedunculated mass was seen in the right arytenoid extending up to the supraglottis. The airway was however adequate.

Rest of ENT, head and neck examination was normal. Contrast Enhanced CT scan of the neck revealed a cystic soft tissue mass arising from right arytenoid, extending into supraglottis. Routine blood investigations and chest X-ray were normal. With this, a provisional diagnosis of Right arytenoid cyst was made. The patient underwent excision of the mass under general anesthesia (Fig. 1). The

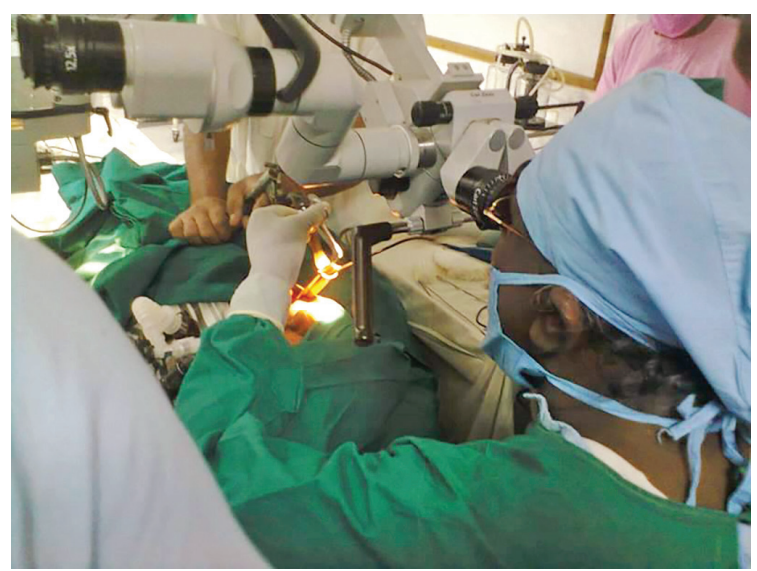

Fig. 1: Mass mobilized

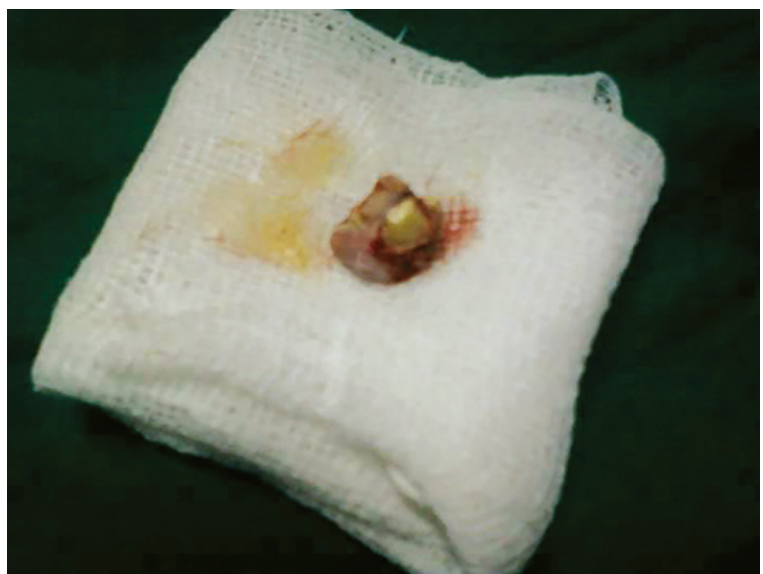

Fig. 2: Excised specimen 


\begin{tabular}{|c|c|c|c|c|c|}
\hline \multicolumn{6}{|c|}{ Pathology Roport } \\
\hline Name: & Mr.Velu & Sample Id: & 259130 & Received on: & $22 / \mathrm{Jun} / 2012$ \\
\hline Age/Gender: & $76 \mathrm{Y} / \mathrm{M}$ & Patient Id: & TRY010026085 & Reported on: & 26/Jun/2012 \\
\hline Ref by: & \multicolumn{3}{|c|}{ Dr. Bhel-main- - } & Path No & H 11005 \\
\hline
\end{tabular}

\begin{tabular}{ll} 
Test & Histopathological examination \\
Clinical data & Cyst from right arytenoid \\
Specimen & Excision biopsy \\
Gross pathology & Specimen consists of cystic structure filled with whitish material measure $1 \mathrm{~cm} . \mathrm{P} / \mathrm{E}-$ \\
\hline Microscopy & $\begin{array}{l}\text { Sections show stratified squamous epithelium with underlying structure filled with wall shows } \\
\text { many lymphocytes. }\end{array}$ \\
Impression & Epidermoid Cyst.
\end{tabular}

Note

Paraffin blocks and slides will be stored for 3 years. The remaining specimen will be discarded after 3 months from the date of reporting.

\#\# End Report \#\#

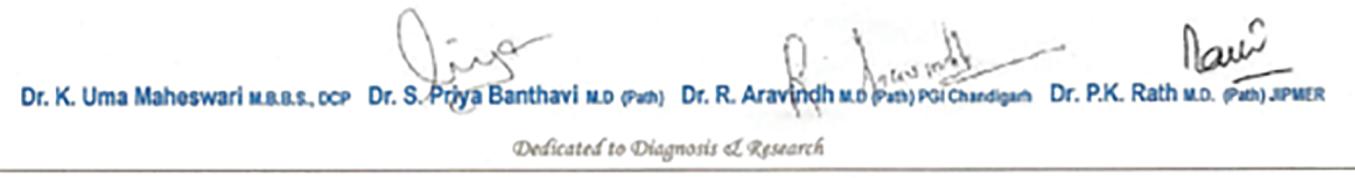

Al slidos are seen by mutiplo Pathologists for better Qualiny

Fig. 3: Histopathology report

mass was mobilized via direct laryngoscopy. After taking representative specimen for histopathology, the mass was excised in toto using coblator (Fig. 2).

Histopathology revealed stratified squamous epithelium with keratin and lymphocytes which was suggestive of epidermoid cyst of arytenoids (Fig. 3). Postoperative period was uneventful and patient is on regular follow-up.

\section{DISCUSSION}

Epidermoid cysts are usually subcutaneous and occasionally epidermal. They are common in skin and very rarely seen in larynx. Epidermal inclusion cysts are not common in mucosal sites such as the larynx; however, these can arise owing to squamous metaplasia of the glands. ${ }^{1}$ The content of the cyst is usually cheesy. 
Presentation varies from dysphonia/hoarseness, dysphagia and dyspnea/stridor. Histologically they can be divided into two groups-True epidermoid cysts and inclusion epidermoid cysts, which are devoid of keratin. ${ }^{2}$ Coblation has been used in infants for the excision of epiglottic cysts with very good results and with less than $2 \mathrm{ml}$ blood loss. ${ }^{3}$ However, there have been no studies on the use of coblator in the treatment of epidermoid cyst of arytenoids due to the rarity of the condition. In our case, the patient had excellent recovery and was discharged after 4 days (after decannulation). Intraoperative blood loss was also very negligible. Coblation uses radiofrequency ablation (RFA) to remove the tissues. This is unlike traditional electrocautery methods. Radiofrequency (RF) energy at low frequencies is delivered to the tip of a bipolar wand. Saline solution acts as a conductive medium and is delivered to the gap between the active and return electrode. The combination of RF energy and conductive medium creates a highly focused plasma field containing highly ionized particles which have sufficient energy to break organic molecular bonds, thus achieving tissue dissection (ablation).

\section{CONCLUSION}

The aim of this article is as follows:

- To emphasize on the presentation of a rare benign neoplasm in a rare site in laryn $x^{4}$

- To highlight the use of new technology in the form of coblation assisted excision of the lesion

- To convey the message that an arytenoid cyst may be considered in the differential diagnosis in a patient presenting with dysphagia and/or hoarseness.

\section{REFERENCES}

1. Yilmaz M, Haciyev Y, Mamanov M, Cansiz H, Yilmaz R. Epidermal inclusion cyst of the larynx. J Craniofac Surg 2011 Nov;22(6):e1-2.

2. Khan NA, Patigaroo AR, Murtaza. Epidermoid cysts of the vocal cords: an undiagnosed clinical entity. JK Sci 2001 OctDec;3(4):179-181.

3. Qiu SY, Liu DB, Huang ZY, Zhong JW, Liu SF. Application of minimally invasive technique of coblation in 30 infants with epiglottic cyst. Chinese J Otorhinolaryngol Head and Neck Surg 2012 June;47(6):496-498.

4. Xanthopulos J, Nousios G, Benis N, Papadopoulos P, Asimakopoulos DJ, Apostolidis T. Large epidermoid cyst of the larynx. Hippokratia 1998;2(4):183-185. 